\title{
DEAF PARENTS AND A DEAF BROTHER: \\ SOME PERSPECTIVES ON IDENTITY AS A HEARING CHILD GROWING UP IN \\ A PREDOMINATELY DEAF FAMILY
}

James Townshend

\begin{abstract}
MY MOTHER FATHER DEAF, MY BROTHER DEAF POINT-LEFT, BROTHER POINT-RIGHT, HEARING, ME WHAT? ME HEARING BUT DEAF HEART.
\end{abstract}

The introduction I have just given is a feeble attempt to express myself on paper in my first language - New Zealand Sign Language. What is missing on paper is the language of my soul, one that is full of expression, emotion and hands. Instead I must think, share and write in the language of my mind. My desire is that as you read, we could see each other face to face. Then I could fully express the message I want to convey. I recall my first job in an office. My supervisor would complain when I would leave my station to talk with a co-worker about a matter. He would say, 'You're wasting time, why don't you just pick up the phone and talk? It's much quicker!' I didn't know then what I know now. I need the whole package: the face, the eyes, the hands, the body, as well as the message of the voice to communicate fully and effectively. So. I share this paper with you in my second language, a language that I have come to love, but which will always remain solely the language of my mind.

I am the first-born hearing child to Deaf parents. I am a CODA, a Child Of Deaf Adults. I have a Deaf brother and a hearing brother.

The experiences of most children of Deaf adults, is usually marked by issues of heavier responsibility at an early age, growing up too quickly, identity confusion and an in-built protectiveness of things Deaf. These were outcomes of my experiences and they were also intensified with growing up with a Deaf sibling. 
When I was growing up, to be Deaf was to be disabled. Whilst we shared a Deaf cultural experience in our family, it was in no way identified as that until much later. Signing or gaining each other's attention, whether it be calling or waving in public was to be as discrete as possible. The stigma of deafness placed upon us by extended family and the community was felt by us all.

My first attempt at communication at ten months of age was the sign for 'HOT', which is expressed by a flat hand brushing off the side of the face. My grandparents reported that in the early years, I was a late talker and began to develop a slight American accent. The only influence they could think of to explain this was the daily exposure to Sesame Street.

I was sent to the local kindergarten at two and a half and had regular speech therapy. Although I could aptly change my communication to suit the environment, I was not aware of the differences and it was not until I was seven that I began to realise that there were some huge differences between my friends' families and my own. The obvious difference being the language which we used but even more different was the way in which we communicated. Whenever friends came over, I would prepare them with an explanation of my family, who was Deaf, who was hearing, what to expect and how to communicate with them. I would then introduce my friends to my family. When I was invited over to play at friend's houses, I was surprised when there was no introduction and we started the business of play. Other families could call out to one another from different rooms, whilst we had to get up and walk to the room the person was in, gain his/ her attention and then begin communicating. Other families argued over which channel to watch, while I was the 'Six O'clock News' interpreter. This was the beginning of the developing of an identity, an identity that was based around acting as a bridge between an isolated Deaf world and a very confusing hearing world.

My brother Steven is two years younger than I. The diagnosis of his deafness was a big shock to my family. My parents did not want their child to face the same difficulties which they faced. As I was already developing NZsL, my communication with a Deaf brother was an extension of the communication that was already happening. Any awareness of having a brother who was different to me did not occur to me until I had first come to realise my own differences to the rest of my family.

My parents decided to send Steven to the Sumner School for the Deaf. This was a difficult decision as the communication which the school offered at the time was oral-aural and the decision was complicated by my parent's many 
negative experiences of education. Around two years into his education, signed English was introduced into the school. My mother said to me at the time that I should learn to sign like her Deaf friend's children. I didn't think this request was strange at the time. I later realised that what she really meant was to learn the signs from signed English. My parent's perception of their communication was that it was not a 'true' language but rather a combination of made up school and home signs that were used with other Deaf friends. My parents and I attended signed English classes at the Sumner School for the Deaf. Interestingly, we did not use this as a mode of communication at home, only when we referred to English in books. Whenever hearing people asked about how to sign something, my parents and I would refer them to the big red book: 'You sign: How are you?, like this: HOW....ARE....YOU.....'

My other brother Andrew is four years younger than I and is hearing. He developed much more quickly in both spoken and sign language. People often get us confused as our voices are so alike. When he began to talk, I was at the stage where I had developed two languages, two languages that were becoming more and more separate. I realised then that I could talk to him and sign to Steven.

Signing and speaking at the same time rarely happened in our family. My grandfather admonished me for not using my voice with my parents. He said, 'You need to talk to your mother! Don't use your hands!' My mother was shocked to learn that I was not using my voice. She said to me, 'You're hearing and you need to talk!' They would sometimes ask other hearing people for feedback about my verbal communication.

As the years went by, my parents would warn me about the big hearing world. They would ask me to look out for my brother Steven. Their concern came from their own experiences of being teased and facing difficulties on a daily basis.

One summer's day, my brothers and I went to the local school pool. A girl stared at Steven. It was obvious what was going on through the girl's mind. Her body language and eye contact and obvious whispering to her friend gave her away. Eventually, she ended this staring by mimicking his signing and slapping her face with her tongue hanging out, as if to say that Steven was intellectually impaired too. I couldn't hold back any longer and ran and dived into the pool and angrily told her to stop doing what she was doing. I followed this up with a rehearsed lecture on how she would feel if she were Deaf or disabled and someone had treated her that way. 
Recently, I reflected on this experience after reading a book on coDAs. I read that oldest siblings often assume certain kinds of family responsibilities, regardless of whether their parents are Deaf or hearing. This was reassuring to know, as I didn't have a frame of reference to put my experiences against. Were my reactions normal? Were they 'over the top'? The swimming pool incident was one of many that occurred. The way in which I interpreted the responsibilities was usually that of a parent. My job was to protect and educate. Part of my reaction was normal big brother protection behaviour but in other ways, who ever heard of an eight-year old charging head first into a public awareness campaign. I told my parents about the swimming pool incident. They said, 'GOOD BOY! TYPICAL HEARING PEOPLE, NOT-UNDERSTAND DEAF!'

As I grew older, I knew I was similar yet very different to my parents and at the same time I was similar yet different to hearing people. When you live in a Deaf family, the ability to hear can be a blessing and a curse at the same time. Throughout my years at home I heard the comments of frustrated extended family members and others. They would say, 'The Deaf can be just so stubborn!' or 'They just don't understand do they?' or 'Oh what a shame, your parents can't hear' or 'It must be so difficult for them and for you', 'Remember to be good to your parents, they need you', 'Weren't you lucky that you weren't born Deaf too' or 'Can you tell your parents that...' or 'Can you explain to your brother that.... These people would mutter to each other in front of my parents or within my earshot. My parent's sharp eyes would pick up on what was going on. The dilemma was always, do I tell my parents what was just said or pretend that it was no big deal. If I told them, it might hurt them or cause another family confrontation and perhaps the extended family would punish me for being a tattletale.

At the same time, to have the ability to hear was also a way to feel good about myself. I knew some things that my parents didn't know. I could explain things and interpret things that other adults couldn't do. In other words, I could feel like a grown-up.

Clashes between Deaf and hearing cultures happened within our own immediate family as we entered our teenage years. If I were having a conversation with a friend on the phone, Steven would walk past, wave his hand and ask, 'WHO THAT?' I would sign, 'GO-AWAY, PRIVATE', and turn my back so I could concentrate. He would continue to ask until I gave in or he would make loud noises so that I would no longer be able to have the conversation. Television and radio also provided the fuel for some big fights. 'WHAT SAY? 
YOU HEARING MUSIC NOT-FAIR! YOU LISTEN ENJOY, WHAT ABOUT ME?' I would reply: 'NOT MY-FAULT BORN HEARING! SHRUG-SHOULDERS!'

At times, I would have an internal argument about these kinds of issues. One side of me would be feeling guilty and saying, 'You really should have told him what was being said because after all if he were hearing he would hear your side of the conversation.' The other part of me would say, 'No, stuff it! It's my time! My friend! You don't have to interpret everything! You have a life too!'

I guess we both had ways of using our gifts of hearing and deafness as ways of making sense of and maintaining some kind of control over our environment. Steven would sometimes get the last word in by signing an angry message and then turn away. If I tried to bang on the floor or tap furiously on his shoulder to gain his attention, he would close his eyes as an act of passive resistance (the hearing equivalent of putting your fingers in your ears while singing, la la la la!). I also could get the last word in, well at least in my own mind anyway, and yell out my final part of the argument. My hearing friends used to say, 'Oh man, it must be so cool to have Deaf parents, you could play really loud music and swear at them'! This attitude always shocked me. My response was usually that from a rehearsed public awareness campaign by explaining, 'Well, no it doesn't work like that, Deaf people feel vibrations and can lip-read really well'!

My parents would often ask me to explain and interpret the hearing world to them as well. They would ask, 'WHAT HE SAY?' or 'WHAT MEAN THAT?' when asking me to explain a letter from the bank about changing interest rates or investments. They were often surprised when I said I didn't know what it meant. Steven would often ask for help with his homework, particularly in relation to English. I would observe Deaf people at the Deaf club talking about 'BLOODY HEARING PEOPLE', 'HEARING WORLD NOT-UNDERSTAND', 'HEARING WAY', 'HEARING PEOPLE KNOW EVERYTHING!'. In my teens, I started to think, 'Well I'm hearing aren't I?' and 'We aren't all like that!' and I think this further fuelled my sense of difference with my peers and the reason that I formed closer relationships with many Deaf and hearing adults instead.

Sometimes, I was asked by my teachers to translate what they wanted to say about my progress at school or about their concerns. This kind of experience also happened at the doctor's surgery. Sometimes I felt good about these experiences as I was made to feel important and grown-up but at other times I 
was scared and uncomfortable. As a child I did not have the voice or the confidence to stand up and say what I needed. As a child I often worried about my future. Was I going to grow up like all these hearing people?

I am often reminded of my childhood experiences when I see other young hearing children of Deaf parents. In this age of technology and increased access, many Deaf parents still over-rely on their hearing children and expose them to experiences that are beyond their years. I try to encourage them that on one hand it is a good thing to give opportunities for children to act responsibly but not too early or too often. They are still children, and need to have a childhood. One example of over responsibility might be if a Deaf parent tells their young hearing child that it is their responsibility to wake the parents up if the smoke alarm goes off, because Mummy and Daddy can't hear! Educating and supporting Deaf parents in raising a hearing child is an area that I am passionate about.

Having a Deaf brother, I witnessed and took part in the developmental, social and educational issues for Steve on a daily basis. Like any siblings we fought, played and learned from each other. I was also fortunate to have the opportunity to meet and form friendships with other Deaf children and codas. These children were Steve's school friends and other Deaf and hearing children at the Christchurch Deaf Club on a Friday night. The way in which sign language is used amongst Deaf peers is very different to the kind of NZSL that the adults used. However, the ability I had to communicate with Steven's friends was also a source of frustration to him. He sometimes felt there was a gross inequality between us as he could not communicate with my friends when they came to play; yet I could with his friends. He would say, 'HEY GO-AWAY NOT-FAIR, MY FRIEND NOT YOURS!'. I also had many opportunities to interpret for Steven and in doing so I was exposed to situations that differed from interpreting for my parents.

I feel that having a Deaf brother intensified my family's connection to the Deaf world. Steve helped me to clearly differentiate between the Deaf and hearing worlds without getting confused with the generational aspects. That is to say, using sign language was not just a tool to translate or get my ideas across to my parents but a way of communicating naturally with people just like me. Having Andrew as a hearing brother also helped me immensely to understand and to appreciate and love the other very important part of me the hearing side. It is wonderful to have another CODA as a brother. As adults we can talk and share our thoughts and feelings as CoDAs. There is no need to explain or justify through the perspectives of the Deaf or hearing worlds. We 
know exactly what the other means. We are able to communicate with each other in a way that can only be described as a fine blend of the two cultures and languages. For example, if I was describing a situation where I was feeling discouraged, I might describe it as, "I felt a bit thhhhhh" (while signing with a flat hand moving down my chest at the same time)

It was not until my late teens that the expression 'Deaf Culture' was used in our household. This cultural perspective put a new light on the experiences in my family. Intuitively I knew it was okay and normal to be Deaf, in fact the majority of the members of my family were Deaf, but now we had a label to explain the difference. The way in which we lived our everyday lives were not wrong but grounded in cultural practices shared by tens of thousands of other people just like us. We could stand up and be proud of our language and use 'BIG' signs if we wanted to. Who cared whether the hearing people stared or what they thought?

I am married to a hearing wife, Liz, who has learnt my first language and thus my blend of cultures. She appreciates this huge part of my life and me. Sometimes we'll go to a restaurant and we will communicate in sign to one another. Sometimes she will ask me if I can't quite explain something, to give it a go in sign. I am hearing on the outside but I often think, dream and solve problems with sign language. I used to think that there must be something wrong with me. My wife has helped me to see that both sides of the coin are to be treasured and shared.

I decided in my early twenties to become a primary school teacher. I initially decided that I would not work in Deaf education when I graduated. At the time I had felt that it was the moment to move away from all things Deaf, I mean after all I was hearing wasn't I? However after a relatively short time of teaching hearing children, I felt a sense of dissatisfaction, so I decided to train as a teacher of the Deaf. I also entered this profession knowing what my parents had missed out on their own education and how much they wished to have access to NZSL as young people. I had the privilege of teaching in one of the first Deaf bilingual programmes at van Asch Deaf Education Centre. In this job, I was able to use my first language everyday with both children and professionals. As a sibling of a Deaf child, I have an insight into the mind of the Deaf learner. I currently work as a resource teacher supporting the people raising Deaf children and the professionals working with them. Working as a teacher of the Deaf I have had the opportunity to not only work with Deaf children but work with professionals who have supported and challenged me 
to discover more about my identity as a CODA. For me, van Asch is a second home. I have a sense of what it must be like for Deaf people to feel that they have finally come home when they meet with other people just like them. This also happened for me when I had the opportunity to attend the 'Deaf Way II' conference and meet a number of other CODAs. Their stories were all different but our feelings were the same. Some of their stories were extremely funny and others brought on a flood of tears. Regardless, there was no need to explain, no need to justify, just to be.

Raising my own children has also helped me to further explore who I am and to define what I value and want to pass on to my children. My daughter has Down syndrome and she has shown me how vital visual communication is for many people. She has also taught me about grieving, accepting loss, joy and finding what is really important about life. There is an unseen purpose is everything we experience.

I still feel at times like a bridge between the expanse of the Deaf and hearing worlds. However, I have come to see in recent years how I can support the affected people on the fringe of deafness to see past the deafness; parents, grandparents, siblings and educators.

I am eternally grateful for the gift of sign language given to me by my parents and this gift that was honed by having a Deaf brother. They gave me the ability to interpret the world in a very different and rich way. A world that is seen through the eyes and expressed through the face and the hands. Deaf people see the beauty of vibrating wings of a dragon fly, while hearing people hear its hum. The way in which the same world is interpreted is very different. For me, the ability to thinking in two languages adds richness in understanding concepts. For example, there are a number of signs for the concept of 'talking'. One sign uses two hands with pointing index fingers while one hand bounces twice on the other. Another sign for 'TALK' is signed in a relaxed way with open handshapes rocking backwards and forwards. This sign expresses the concept of talking in a way that is more intimate, expressive and represents two people sharing heart to heart. The English word for 'talk' doesn't quite express the idea in the same way.

Sometimes I feel that the hearing world in which I must live is more restrictive. Communication in the hearing world is more verbal, mental, confined and contrary to the way I have been brought up. The hearing world is like a box around my mouth. I have had to learn not to use so much facial expres- 
sion, nodding and prolonged eye gaze with hearing people. I realise now that the world offers both sounds and silence. I can be both and no longer have to be caught between the two. I am a hearing person with a Deaf heart. 